\title{
Fritz Bauer (1903-1968). Jurista por el sentido de la libertad ${ }^{1}$
}

Fritz Bauer (1903-1968). Lawyer for the sense of freedom

Dr. Irmtrud Wojak Irmtrud.Wojak@gmx.de Universidad de Bundeswehr BUXUS STIFTUNG gmbH

Múnich

\section{Resumen}

Este ensayo resume los grandes temas en la vida y obra de Fritz Bauer (1903 -1968), el jurista alemán que además reformó el sistema judicial de su país. En 1933 fue detenido por sus convicciones socialdemócratas y encerrado en un campo de concentración, luego de ser liberado sobrevivió en el exilio. En 1949, Bauer regresó a Alemania. Hizo de la desnazificación su tarea principal, entregó a los israelíes los datos determinantes del escondite de Adolf Eichmann y llevó a juicio a los asesinos de Auschwitz.

Palabras clave: Historia de un sobreviviente - Resistencia contra el Nazismo - Proceso de Auschwitz - Fracaso de desnazificación - Alemania.

\footnotetext{
${ }^{1}$ Traducción y redacción: Isabel Mardones y Lore Hepner.
} 


\begin{abstract}
This essay summarizes the themes in the life and work of the German jurist and legal reformer Fritz Bauer (1903-1968), who was interned in a concentration camp as a Social Democrat by the Nazis in 1933 and survived in exile after being released. In 1949 Bauer returned to Germany, where he worked for denazification, provided the Israelis with key information on Adolf Eichmann's whereabouts, and initiated the trial of the Auschwitz murderers.
\end{abstract}

Key words: Survivors' story - Resistance against National Socialism - Auschwitz trial Failure of denazification - Germany.

La vida de Fritz Bauer es la historia de un jurista y socialdemócrata alemán en el catastrófico siglo XX, especialmente es una confrontación con la historia reciente, la política y lo jurídico, posterior a 1945, hasta nuestros días.

Muchos no conocerán a Fritz Bauer y algunos pocos relacionarán su nombre a otros eventos. Eso ya lo previeron los contemporáneos de Fritz Bauer y dijeron que su obra recién surgiría más tarde en el recuerdo. Este artículo tiene como objetivo presentar su vida y obra, o mejor dicho, las principales características y motivos de la impresionante vida de un jurista ${ }^{2}$. (Wojak, 2009)

Fritz Bauer nació en Stuttgart en 1903. Después de la Segunda Guerra Mundial él mismo habló de la nostalgia que sentía por Stuttgart, durante el primer viaje que hizo de visita a Alemania, y en la alegría del reencuentro recordó los Käsespätzle, un plato típico que comió por un marco en un restaurante de la ciudad. De pura nostalgia se "robó" el menú y se lo llevó consigo de regreso a Dinamarca, su país de exilio durante trece años.

Seguramente hay cosas que contar de Stuttgart, donde pasó su juventud. Desde Stuttgart su padre siguió el llamado del emperador Guillermo Segundo y se enroló en la Primera Guerra

\footnotetext{
${ }^{2}$ A menos que se indique lo contrario, toda la información en detalle figura en la biografía de Fritz Bauer: Wojak (2009).
} 
Mundial. En Stuttgart, Fritz Bauer fue al tradicional colegio superior Eberhard Ludwig (Eberhard Ludwig Gymnasium), donde vivió la revolución de 1918/19 (que en realidad no fue una revolución). Desde Stuttgart partió a estudiar y finalmente se recibió como el juez más joven de Alemania. Como estudiante, la ola de renovación que surgió después del colapso del Imperio lo llevó a iniciarse en la vida política: se unió a los socialdemócratas. Hasta el último día luchó por mantener vigente a la república.

Con la llegada de los nazis al poder se terminó tempranamente la carrera del joven jurista. Casi inmediatamente fue tomado preso, encerrado en un campo de concentración y expulsado del Poder Judicial. A fines de 1935, a los 32 años, logró escapar a Copenhague. Cuando los nazis decidieron aplicar también en Dinamarca la "solución final" - Fritz Bauer provenía de una familia de origen judío-, escapó en 1943 a Suecia. Al finalizar la guerra regresó a Dinamarca. No logró volver a su amada Stuttgart natal, ya que en la justicia Alemana no hubo nadie que lo convocara desde el exilio. Sin emabrgo, algunas semanas antes de la fundación de la República Federal y de la aprobación de su Constitución (Grundgesetz), en 1949, regresó de todas formas a Alemania, eso sí que a la ciudad de Braunschweig, donde pronto fue nombrado director del juzgado estatal. Luego, en 1950, llegó su nombramiento como fiscal general en el tribunal superior de Braunschweig. En 1956 el Ministro del Estado de Hesse y también Secretario de Justicia lo convocó en el cargo de Fiscal General en Frankfurt. Allí trabajó doce años, hasta 1968.

La vida y el pensamiento de Fritz Bauer estuvieron marcados por las profundas divisiones políticas y sociales provocadas por las dos guerras mundiales. También lo influenciaron su origen judío y el espíritu de emancipación que regía en la casa de sus abuelos maternos. En cambio, en su hogar paterno se mantenía distancia de los ritos religiosos y él mismo se declaraba "sin confesión".

El mundo de sus ideas, sus sueños y esperanzas, acompañan mi trabajo de investigación hace muchos años. También sus derrotas, las que vivió como jurista, comprometido con la política, siendo quien después de 1945 impulsó con todas sus fuerzas un "nuevo derecho alemán" y la reconstrucción de la democracia. Su destino como perseguido del régimen nazi y como exiliado nunca lo paralizó, más bien lo impulsaba en su insistencia de siempre avanzar.

"Regresé”, decía él mismo, "porque creía poder traer conmigo algo del optimismo y la fe de los jóvenes demócratas de la República de Weimar y aportar algo del espíritu y 
voluntad de resistencia de la emigración para luchar contra la injusticia del Estado (...)

Quería ser un jurista que no solo sirviera de los dientes para afuera al derecho y la justicia, la humanidad y la paz"3 (Bauer, 1962a, 657 f.).

Con este "programa" regresó Fritz Bauer, con la esperanza de poder contribuir a un nuevo comienzo fundacional e impulsar la urgente y necesaria "revolución espiritual de los alemanes". Consideró que confrontar a las raíces del nacionalsocialismo era inevitable. Los alemanes deberían tener un "día de juicio" sobre sí mismos, sobre los peligrosos factores de la historia, sobre todo aquello que era inhumano. ${ }^{4}$ (Bauer, 1965a, $66 \mathrm{f}$.)

\section{¿Se han cumplido las expectativas de Fritz Bauer?}

Primero y principalmente lo conocí como el radical esclarecedor de los crímenes nazis, quien daba advertencias incómodas; era el marginado, quien permanentemente sostenía un espejo frente a sus contemporáneos, espejo en el que no querían mirarse. Bauer no podía ni quería dejar en paz al pasado. Provocó la mala conciencia de los hechores y colaboradores del régimen nazi, al confrontarlos con todos los detalles de los crímenes de la llamada "solución final”. Fue el fiscal que logró llevar a los asesinos de Auschwitz a juicio, como lo formuló sucintamente la jurista Ilse Staff (Staff, 1968, 2858). Fue por eso que lo persiguieron con cartas de amenaza y hostilidades hasta su muerte.

No recibió ningún premio en vida. El fiscal general de Braunschweig y de Hesse, que inició una serie de debates políticos durante su vida y nos enfrentó a los desafíos de la realidad y a lo que significa ser seres humanos, fue prácticamente olvidado por la política y la justicia "oficial", incluso por su propio partido. Recientemente esto cambió para bien, sobre todo por la película de Ilona Ziok, Fritz Bauer: muerte a plazo (CV Films Berlín, 2009). La película resulta provocativa para quienes se opusieron a su trabajo y no querían escuchar, ni ver o saber nada de sus demandas en favor de los derechos humanos, tanto en la política y la justicia, como tampoco en la historiografía.

\footnotetext{
${ }^{3}$ Cita tomada de un artículo sin título de F. Bauer para el Deutsche Post, año 14 (1962), H. 24, p.657 y ss.

${ }^{4}$ El Ministerio de Culto de Renania-Palatinado rechazó la propuesta del Círculo de Jóvenes de la región para incluir la conferencia de Bauer, de la que proviene esta cita, como parte del material de enseñanza a disposición de las escuelas superiores. Cuando posteriormente se llegó a un "gran petitorio" de los socialdemócratas (SPD), dentro del debate del parlamento regional los liberales (FDP) los acusaron de tener una relación deficitaria con la historia,un diputado conservador del CDU declaró que el "Tercer Reich" habría "caído como una sombra oscura sobre Alemania". (Staff, 1988, p.447)
} 
Sacar a Fritz Bauer del olvido y darle el sitial que se merece en la historia judicial significa, y esto lo comprobé durante mis propias investigaciones, abrir viejas heridas. Incluso entre los que lo amaron y se hacían graves reproches después de su temprana muerte. “¿Es que nos hemos preocupado por Fritz Bauer? ¿Y qué hicimos por él?”, se preguntaba en el funeral de Bauer el ex fiscal de los juicios de Núremberg, Robert M. W. Kempner, que había percibido la amenazante resignación de Bauer. En el fiscal de Hesse veía al vocero de los asesinados y a la persona que se preocupaba de que los sobrevivientes de los campos de concentración, que habían venido a Alemania como testigos del juicio, fuesen tratados con esmero: "Ideas en las que antes nadie había pensado". Para él, Bauer fue el mayor embajador que tuvo la República Federal, como dijo Kempner a los petrificados asistentes (Kempner, 1969, 25 f.).

En las investigaciones para la biografía de Bauer aparecen una y otra vez omisiones y obstáculos en la persecución jurídica y las sentencias por los millones de crímenes, que saltan al primer plano de la historia: la integración de los juristas nazis en la nueva justicia alemana, además de los funcionarios nazis enquistados en el aparato estatal, junto a la falta de voluntad de la justicia y de la policía de encontrar a los criminales y de perseguir con las herramientas jurídicas a su alcance a los perpetradores de los asesinatos masivos. Además, en los procesos contra los tropas de asalto (Einsatzgruppen) y homicidas de los campos de concentración, se tendió a aplicar el principio de "ayudantes", que convertía a los asesinos en masa en simples ejecutores de órdenes superiores, como si fueran marionetas fácilmente manipulables de un régimen criminal, como si no hubiera habido nazis, y peor aún, con una completa falta de empatía por las víctimas y los sobrevivientes.

La vida y obra de Fritz Bauer no se deja compatibilizar con la entretanto famosa versión de la historia alemana de éxito a contar de 1945, como aún intentan mantenerla sus opositores políticos para acallarlo. La vida y obra de Bauer estuvieron marcadas por dos guerras mundiales, por discriminación, antisemitismo, genocidio y también por una nueva marginación y represión después de 1945. Tal vez tuvo más peso en el hecho de que su visión fuese indeseada en la época del milagro económico alemán, porque postulaba que la investigación histórica sobre los motivos, el esclarecimiento jurídico de los crímenes y las condenas ante los tribunales, contribuirían a aclarar el pasado. La gran mayoría de los alemanes quería olvidar y poner cuanto antes un punto final a ese pasado. 


\section{¿Fueron en vano entonces los esfuerzos de Fritz Bauer? ¿Y qué fue lo que no le permitía darse por vencido?}

Fue el amor de su madre, que lo protegió de niño y reforzó su autoestima. Ella le dio a Bauer una cita bíblica para la vida, cuando fue acosado por los ataques antisemitas de sus compañeros y se acercó a ella con la pregunta: “QQué es realmente Dios?”. Fritz recordaba literalmente esta escena y reconocía que nunca olvidó la respuesta, la que se convirtió en la guía de su vida y su trabajo: "decía, 'Lo que no quieres que te hagan a ti, ¡no se lo hagas a otro!"” (ALS SIE NOCH JUNG WAREN, julio 2003). Ya en esa fase temprana escogió su senda y se decidió por una existencia política. Puesto que este lema, expresado más actual y políticamente, encierra el núcleo de la democracia y los derechos humanos, tal como aparecen en de la Constitución alemana de 1949: "La dignidad del hombre es intocable". (Constitución Art. 1)

Esa fue su concepción de la justicia: que el Estado y la sociedad no pueden hacer del mandamiento del amor al prójimo el contenido de su legislación. "Humanamente no se puede exigir tanto, es casi sobrehumano”. (Bauer, 1966, p.12) Pero deben respetar otro mandamiento como guía, el que dice, “¡No hagas daño a los demás!” (Constitución Art. 2, Párr. 1 y 2). Esta máxima, incluida en las religiones del mundo desde hace siglos y que llama a la activa omisión, es la que guio a Bauer toda su vida. En la época de cambios sociales de los años 1920 fueron tres hechos los que marcaron su deseo de ser jurista y de participar en la política de la República de Weimar:

Al comienzo de sus estudios descubrió al jurista Gustav Radbruch (1878-1949) y, si bien no fue su profesor, ya que Radbruch dejó la docencia por la política como socialdemócrata, leyó con entusiasmo sus escritos, como la Introducción a las Ciencias Jurídicas. Radbruch distinguía "entre dos tipos de juristas", tal como escribió Bauer, "el jurista apegado al orden y el jurista apegado a la 9" - y ese último era lo que Bauer quería ser. (Bauer, 1955, p.41)

El segundo hecho fue el atentado en 1922 contra el Canciller del Reich, Walther Rathenau (1867-1922), un político prometedor al que los extremistas de derecha querían eliminar porque había logrado acuerdos con los opositores de la época de la guerra y de la post-guerra, con lo que lograría extender la sobrevida de la república. "El enemigo está en la derecha", era el grito conmovedor que impulsó al estudiante Fritz Bauer y a sus compañeros a acciones inusuales. Alarmados por las concentraciones y las marchas de los nazis, que desde Múnich buscaban hundir a la República de Weimar, apelaron al escritor Thomas Mann (1875-1955) 
para que no callara y defendiera también la patria republicana. "Thomas Mann”, recordaría Bauer después, "al que amábamos por sobre todo y que había marcado nuestra juventud desde Tonio Kröger, ahora estaba con nosotros". Efectivamente, el escritor les respondió de inmediato, “que sí, teníamos razón y él estaba de nuestro lado". Lo que siguió es el conocido discurso de Thomas Mann sobre la República alemana, el que todavía en ese mismo año de crisis fue difundido al mundo. (AL SIE NOCH JUNG WAREN, julio 2003)

La tercera personalidad que determinó el destino político de Bauer fue el socialdemócrata Kurt Schumacher (1895-1952), quien empezó a ser influyente en Stuttgart después de 1920 y atrajo con sus ideas al futuro juez (más tarde refundaría el partido socialdemócrata y sería el mayor contrapeso, desde la oposición, para Konrad Adenauer). Apenas rindió su examen final, Bauer se presentó ante el redactor ejecutivo del diario Schwäbische Tagwacht, "con la iniciativa de hacer algo" (ALS SIE NOCH JUNG WAREN, julio 2003). Bauer se convirtió en un miembro activo de la organización de protección de la república "Bandera del Reich Negro/Rojo/Oro" (Reichsbanner Schwarz Rot Gold) y luego fue su dirigente en Stuttgart. En 1932/33 seguramente no habría estado en contra de una coalición de partidos de izquierda, que, mancomunados, hubiesen podido derrotar a los nazis.

Los años posteriores a 1933 fortalecen sus principios de vida, los que exigen máxima valentía y coraje civil. Demasiados -y eso lo repetía constantemente- habían sido los seguidores del injusto régimen nacionalsocialista que desviaron la mirada o callaron:

“(...) en los procesos de 'arianizaciones', en la deportación de millones, en las duras y crueles sentencias judiciales, en los campos de concentración y los de exterminio, en las tropas de asalto ("Einsatzgruppen" - I.W.) del Este y muchos otros actos de injusticia". (Bauer, 1965a, 32)

Como causal de esta barbarie, consideraba el jurista, la disolución de la conciencia del estado de derecho. Creía en la razón y decía también, que el sufrimiento de millones de personas después de 1933 debería apelar al corazón de los demás. Al mismo tiempo su escepticismo frente a principios y valores era reforzado a partir de su propia experiencia con el régimen nacionalsocialista. Consideraba que moralmente las personas estaban obligadas a ayudar a los judíos en sus sufrimientos. Toda la vida estuvo en la "Búsqueda de la Justicia" -como tituló Bauer su publicación de 1965-, en la que elaboró estos principios, mientras al mismo tiempo sentía que todo el esfuerzo había sido en vano. Pero no se dio por vencido cuando se trataba 
de configurar el presente y el futuro en un marco de derecho y justicia, porque todos los hombres finalmente buscan la verdadera justicia.

Fue esta esperanza, esta nostalgia humana la que hizo regresar a Fritz Bauer a Alemania después de haber estado preso en un campo de concentración y en el exilio.

A pesar de que la decisión no fue fácil y además se le hizo más difícil aún, ya que en Alemania los re emigrantes políticos no eran precisamente recibidos con los brazos abiertos, ¡todo lo contrario!, Bauer tuvo que comprobar que la mala conciencia de los alemanes incluía una buena porción de ira, no solo por la destrucción que causaron los bombardeos, cuyos restos ahora se hacían desaparecer en tiempo récord. Como él mismo lo percibió, lo que más pesaba en las conciencias era el tener que enfrentarse a "los otros", a aquellos que se habían resistido a adaptarse al nacionalsocialismo y ahora querían regresar. $Y$ en especial, frente a las víctimas y sobrevivientes, con cuyos destinos los alemanes estaban siendo confrontados.

Hannah Arendt (1906-1975), quien estuvo casi al mismo tiempo que Fritz Bauer de "visita" en Alemania en 1950, lo expresó así:

La visión que ofrecían las ciudades destruidas y el hecho de que se sabe lo ocurrido en los campos de concentración y exterminio, ha hecho caer sobre Europa un manto de tristeza (...) Pero en ningún lugar esta pesadilla de destrucción y miedo se percibe menos y en ningún lugar se habla menos de ello que en Alemania. (Arendt, 1950, pp.43-45)

En esta carencia de sentimientos, que era "una huida de la realidad", Arendt reconoció “naturalmente también una huida ante la responsabilidad. (Arendt, 1950, pp.43-45)

La Guerra Fría y la desnazificación que los aliados suspendieron rápidamente -y que era repudiada por los alemanes- prontamente salieron al encuentro de esta huida ante la responsabilidad. Cuando Fritz Bauer asumió su cargo en 1949 como director del Juzgado Regional de Braunschweig, ya reinaba la Guerra Fría con todo su poderío, Berlín estaba bajo la amenaza soviética, los norteamericanos armaron el puente aéreo, y la República Federal de Alemania debía ingresar a la OTAN antes de que pudiera tomar decisiones por sí misma. En todas partes uno se encontraba con circunstancias contradictorias: por un lado, la llamada “confrontación con el pasado" ni siquiera había comenzado en 1949, por otro lado, se hacía todo lo posible por eliminar la desnazificación de la agenda cotidiana. 
En muchos juicios Fritz Bauer se sintió retrotraído al año 1933 y debió lidiar con la noción de que el Poder Judicial se había dejado abusar como instrumento de la voluntad del régimen nazi. Un Poder Judicial que después de 1945 no había sido modificado y no vivió un recambio en sus fundamentos. En los procesos contra los crímenes nazis tomó conciencia de que la criminalidad cotidiana era percibida de un modo muy diferente por la población, en comparación con los crímenes durante el régimen nacionalsocialista. No tan solo la burocracia estatal, sino en especial los jueces, pusieron en entredicho que con el año 1933 hubiese habido más que una simple reforma al Estado, negando la conversión de Alemania de Estado de Derecho (Rechtsstaat) en un estado de Injusticia, un Estado de "No-derecho", del que eran responsables todos los involucrados.

Por esta razón, además de conocer los hechos, los procesos por los crímenes nazis adquirieron para Bauer un sentido: dar nueva relevancia al derecho a resistir y a los actos de resistencia (Bauer, 1962b; Fröhlich, 2006). El desarrollo político en Baja Sajonia le ofreció la posibilidad de instituir un ejemplo durante el juicio contra Otto Ernst Remer, cofundador de los extremistas de derecha en octubre de 1949, un partido de orientación neonazi con el nombre de "Partido Socialista del Reich" (Sozialistische Reichspartei/ SRP).

Aún antes de los sorpresivos resultados del parlamento regional, en el que Remer encontró el apoyo de las asociaciones de soldados y de los extremistas de derecha, durante una concentración en 1951, Remer despreció públicamente a los miembros de la resistencia del 20 de julio de 1944: "Habrían cometido traición a la patria, y más aún, se habrían dejado pagar desde el extranjero". Un insulto que el Ministro del Interior decidió responder con una querella. El proceso terminó en marzo de 1952, con la completa rehabilitación del 20 de julio de 1944 y la evidencia de que los conjurados no solo querían terminar la guerra (lo que habría salvado la vida de cientos de miles de soldados), sino que además querían eliminar un régimen criminal. (Bauer, 1952; Molitor, 1952)

La Segunda Guerra Mundial ya estaba perdida y el pueblo alemán, aclaró Bauer en su alegato, había sido "totalmente traicionado", justamente por eso no podrían haber cometido "traición a la Patria". El “Tercer Reich" había sido un "estado de No-derecho, un estado de Injusticia, contrario a toda tradición convencional y por lo tanto no válido"; tal estado de injusticia, que cada día realiza más de 10 mil asesinatos, justifica la resistencia de cualquier persona. Y por ende, cualquiera habría tenido "el derecho de prestar auxilio a los judíos y a los agentes de inteligencia del exterior". Una frase de su alegato culminaba con la aseveración: "Un estado 
de injusticia como el Tercer Reich es en ningún caso susceptible de traición a la patria”. (Bauer, 1952, p.171)

Con el proceso contra Remer, Fritz Bauer ingresó a la historia de Alemania Federal como connotado acusador, que - eso sí - tenía muchos enemigos. Hizo que sus contemporáneos se le opusieran, porque declaró, que después de 1933 habría sido el derecho y el deber de cualquier persona prestar ayuda a los judíos y a todos los perseguidos por los nazis. En 1956 se trasladó a Hesse y desde ese momento su preocupación principal fue llevar a juicio a la llamada "solución final de los judíos", algo que ninguna fiscalía alemana había llevado a cabo.

En este intento, varias casualidades le serían de ayuda, en especial, en el caso del especialista en deportaciones Adolf Eichmann. Un ex prisionero de un campo de concentración informó tempranamente a Fritz Bauer acerca del lugar en Argentina donde vivía el ex miembro de la SS. Y aunque no se sabe con exactitud a qué instituciones Bauer entregaba sus informaciones, de todas formas tuvo una participación importante en la captura de Eichmann por parte de los israelíes (Wojak, 2013). Menos suerte tuvo en los casos de Mengele, médico de los campos de concentración, y en el caso de Bormann, el sucesor de Hitler.

Fueron muchas las casualidades las que ayudaron a Bauer, o mejor dicho, el accionar comprometido de muchos individuos. Sobre todo, cuando logró que en 1959 se le otorgara a su fiscalía la jurisdicción o competencia para iniciar la investigación contra los perpetradores de Auschwitz. La variedad y extensión de su ininterrumpida capacidad investigativa superaron todo lo imaginable y llevaron a la detención de diversos funcionarios de Auschwitz. Con el apoyo de Hermann Langbein (1912-1995), secretario general del Comité Internacional de Auschwitz en Viena, Bauer logró que testificaran 211 víctimas y sobrevivientes, en el proceso realizado en Frankfurt. (Langbein, 1995; Wojak Ed. 2004)

Solo dos años después del proceso de Eichmann en Jerusalén, el proceso de Auschwitz se convirtió en el proceso más extenso hasta esa fecha en la historia judicial alemana.

Fueron condenados finalmente veinte criminales de Auschwitz que, según sostuvieron sistemáticamente sus defensores, solo actuaron siguiendo órdenes directas. Órdenes son órdenes y la ley es la ley... La mayor carga recayó sobre los sobrevivientes, que como testigos debieron revivir todo lo sufrido. Junto a los historiadores contemporáneos que Bauer había incluido como peritos calificados, se develó un cuadro completo de la llamada 
"solución final" (Buchheim, Broszat, Jacobsen y Krausnick, 1965). La sentencia se dio a conocer el 20/21 de agosto de 1965. Desde ese momento el mundo entero pudo saber lo que fue Auschwitz - ¡ya nadie lo podría negar!-.

¿Podía el Fiscal General Dr. Fritz Bauer estar orgulloso o satisfecho? Sí y no. Para él, cada funcionario de Auschwitz, es decir, todos los acusados eran perpetradores y asesinos. Para el tribunal, empero, 10 de los 20, es decir la mitad, fueron considerados meros ayudantes -lo que entretanto la Corte Suprema Alemana, el tribunal de mayor nivel, introdujo como jurisprudencia y se ha convertido en praxis habitual-. Tanto los fiscales como los abogados querellantes habían alegado unánimemente en esos diez casos su condición de asesinos o de genocidas.

Pero el genocidio (Völkermord), enfatizó el presidente de la corte, Hans Hofmeyer (19041992), no estaba incluido dentro de la jurisprudencia, sino que los jueces debieron partir a Auschwitz en diversas responsabilidades personales. Con ello, tarde o temprano, se explicitó, que en Auschwitz también hubo funcionarios que no dispararon, que no colocaron inyecciones de fenol a las víctimas, que no golpearon prisioneros hasta la muerte o que les quitaran el alimento hasta hacerlos morir de hambre. Lo grotesco de esta diferenciación se evidenció en el caso Klehr. Este enfermero había colocado inyecciones de fenol en el corazón de al menos treinta mil personas. Supuestamente, no lo hacía por gusto, sino que había sentido profunda compasión por sus víctimas, se señaló en el proceso. Si el médico del campo no venía a trabajar, Klehr actuaba por propia iniciativa, y por sobre todo escogía a judíos. (Wojak Ed., 2004; Wojak, 2009)

¿Pero, quién llevaba los prisioneros seleccionados donde Klehr, quién los empujaba por la puerta del supuesto consultorio y ayudaba en la selección previa en las barracas? ¿Quién anotaba los nombres de los candidatos a morir, quién llevaba las listas a la oficina de inspección, quién vigilaba y organizaba su transporte a las cámaras de gas? ¿Quién daba la orden de traer Zyklon B? Pienso que esta enumeración grotesca es suficiente. Pero como ya dijimos, para el tribunal los asesinos eran solamente Klehr y Kaduk, Stark, Boger y Bednarek. Los demás, que sabían tanto como los asesinos acerca de estos excesos y de la función de Auschwitz, es decir, de asesinatos por millones, lograron salvarse por cumplir el rol de asistentes ("Gehilfen"), ya que habían "prestado ayuda colectiva a asesinatos colectivos". Incluso el asistente del comandante del campo, Robert Mulka, quien mantenía en 
funcionamiento la maquinaria de la muerte y daba las órdenes correspondientes, para el tribunal era tan solo un ayudante. (Wojak Ed. 2004, 332 f.)

Con eso no podían estar de acuerdo Fritz Bauer ni las víctimas de Auschwitz. El proceso de Auschwitz privatizó "los hechos colectivos" y así los debilitó, criticó el fiscal general. La condena desconoció, por no decir que humilló, en su sufrimiento a los sobrevivientes y las víctimas. (Bauer, 1965b, 84)

Pero a pesar de las desilusiones y los retrocesos, el Fiscal General no se dio por vencido. Fritz Bauer no solo logró llevar a cabo el proceso de Auschwitz, sino tantos otros juicios cuya documentación -como un mosaico - componen la imagen del horror y de la injusticia nazi en casi cada ámbito de la vida:

- Los procesos contra los responsables de la eutanasia nazi,

- una investigación contra los soplones en la justicia nazi (los que en conjunto mantuvieron silencio cuando el Ministro de Justicia, Schlegelberger, les ordenó no hacer nada contra los asesinatos institucionales),

- procesos relacionados con la jefatura de las SS,

- impulsos para el proceso en Darmstadt contra los tropas de asalto ("Einsatzgruppen"),

- en 1966, la querella por asesinato masivo en Babij Jar contra los "Sonderkommandos",

- el proceso contra Krumey y Hunsche, asistentes de Eichmann en la deportación y la muerte de unos 400 mil judíos húngaros,

- la querella contra Beger y otros, por la llamada "colección de esqueletos judíos" en la Universidad de Estrasburgo. Un museo de muertos, es decir de judíos asesinados que habían sido escogidos en Auschwitz,

- y finalmente, el caso de Adolf Heinz Beckerle, presidente de la policía de Frankfurt durante el régimen nazi, quien entre 1941 y 1944, como "encargado del Reich" en Sofía, ayudó a Eichmann a poner sus garras sobre varias decenas de miles de judíos de Tracia y Macedonia. (Wojak, 2009)

Con los procesos Bauer nos quiso mostrar "cuán delgada fue y es la piel de la civilización”. Quería mandar una señal potente acerca de “lo que en verdad debe significar 'ser humano', lo 
que debemos aprender al respecto y lo difícil que resulta respetar este conocimiento para los acusados y para los demás" (Bauer, 1965c, p.176). Quiso aproximarse a las raíces del accionar nacionalsocialista más que juzgar en primera línea. Con la idea de "un día de juicio" se refirió a la auto reflexión. Para expresarlo en palabras de su amigo Theodor W. Adorno: "Es necesario conocer los mecanismos que logran que haya seres humanos capaces de cometer tales actos y ello (....) debe despertar una conciencia general" (Adorno, 1966, p.90). Fritz Bauer quería que reconociéramos que Auschwitz tiene que ver con los hombres, con nosotros mismos.

Las raíces del accionar nazi las reconoció en la confianza en el Estado autoritario y en la carencia de coraje civil. Con todas sus fuerzas luchó por el reconocimiento político y el derecho a la resistencia. Una de sus últimas conferencias trató sobre "Desobediencia y resistencia en la historia y en la actualidad" (Bauer, 1968). Aquello fue el 21 de junio de 1968, en el sitio histórico de la Universidad de Múnich. Ese lugar debía llevar a comprender y contextualizar a los hermanos Scholl y a la "Rosa Blanca" ("Weiße Rose"), y en su disertación Bauer desplegó la historia del derecho a la resistencia. La conferencia en Múnich fue un alegato en favor de la desobediencia y resistencia contra el poder estatal usurpado y fue también un documento que resume su compromiso de vida:

Todas las acciones realizadas en nombre del derecho a la resistencia -comenzó- incluso las abstenciones en nombre de la desobediencia, son el intento de una crítica, una influencia, una corrección de los hechos del estado que se toma tal vez con liviandad. La medida, al igual que el derecho a la resistencia, no es un nuevo derecho, sino uno muy antiguo que de acuerdo a la resistencia ha sido torcida por el estado. El derecho a la resistencia no significa revolución, sino la concreción de un derecho ya válido, pero no vigente. (Bauer, 1968)

Refiriéndose a los hechos de la actualidad, Bauer enfatizó con satisfacción que nuestro Estado, nuestro derecho, nuestra Constitución imponen "una obligación de desobediencia", tanto a funcionarios como a soldados. Entendido bien, es un derecho a poder desobedecer órdenes y obliga a la desobediencia "cuando una orden (...) daña la dignidad de las personas". Concluye enfatizando que, "nuestros procesos criminales contra los perpetradores nazis se basan sin excepción en el principio del deber a desobedecer”. (Bauer, 1968) 
Para Fritz Bauer, cuya meta era reconocer la responsabilidad personal, de la que él tampoco se excluyó, la enseñanza que dejaron los procesos es que "en nuestra vida existen límites, más allá de los cuales no debemos participar” (Bauer, 1968). La enseñanza más decisiva de los procesos contra los victimarios nazis consistía para él en que debían haber dicho: ¡no!

Hoy sabemos que parte del proceso de adaptación a un poder externo pasa por percibir que el dolor, el que es sentido como debilidad, puede dirigirse contra nosotros mismos, pero también contra los demás (Gruen, 2002; Gruen, 2015). Es el temor frente al propio dolor lo que siempre lleva a la traición del hombre por el hombre. Es la voluntad de tomar compromisos equivocados y aliarse con el que supuestamente es más fuerte, en vez de resistir a la conformidad y a la participación con el rebaño.

La enseñanza que podemos extraer, es que los pocos que tienen el valor de levantarse frente a los extremismos de derecha, los neo nazismos y la injusticia, los que luchan por la humanidad y los derechos humanos, deben ser nuestro acicate. Por historias de vida como la de Fritz Bauer y otros sobrevivientes y miembros de la resistencia, sin importar el lugar del mundo, se refuerza el pensamiento y el accionar de los seres humanos. En la medida que investiguemos acerca de sus vidas y las hagamos presente continuamente, seguirán vigentes como fuentes de energía y podemos seguir aprendiendo de ellos para nuestro actuar en la sociedad.

Como decía Fritz Bauer:

"De la tierra no podemos hacer el cielo, pero sí podemos preocuparnos de que no se convierta en un infierno". (Bauer, 1955, 49) 


\section{Bibliografía}

Theodor. A. (1966). Erziehung nach Auschwitz (1966). En Theodor W. Adorno (1971), Erziehung zur Mündigkeit. 1era edición, Frankfurt am Main: Suhrkamp, 88-104.

ALS SIE NOCH JUNG WAREN (julio 2003). Dr. Fritz Bauer, Documental televisivo de 1967, Entrevistadores: Harpprecht, Renate / Müller Scherak Produktion; para Westdeutschen Rundfunk (WDR), Colonia. Transcripción de la entrevista: Susanne Krejcik.

Arendt, H. (1950). Besuch in Deutschland 1950. Die Nachwirkungen des Naziregimes. En Hannah Arendt, Zur Zeit. Politische Essays. Ed. por Marie Luise Knott (1986). Berlin: Wagenbach, 43-70.

Der Auschwitz-Prozeß. (2004). Tonbandmitschnitte / Protokolle / Dokumente. Fritz Bauer Institut y Staatliches Museum Auschwitz-Birkenau (Eds). Digitale Bibliothek Nr. 101 (DVDRom). Berlin.

Bauer, F. (1952). Eine Grenze hat Tyrannenmacht (1952). En Fritz Bauer, Die Humanität der Rechtsordnung. Ausgewählte Schriften. Ed. por Joachim Perels e IrmtrudWojak (1998).Frankfurt am Main, New York: Campus, 169-179.

Bauer, F. (1955). Im Kampf um des Menschen Rechte (1955). En Fritz Bauer, Die Humanität der Rechtsordnung. Ausgewählte Schriften. Ed. por Joachim Perels e Irmtrud Wojak (1998). Frankfurt am Main, New York: Campus, 37-49.

Bauer, F. (1962a). Cita de un artículo sin título de F. Bauer para la Deutsche Post, 14 (24), $657 \mathrm{f}$.

Bauer, F. (1962b). Widerstandsrecht und Widerstandspflicht des Staatsbürgers (1962). En Fritz Bauer, Die Humanität der Rechtsordnung. Ausgewählte Schriften. Ed. por Joachim Perels e Irmtrud Wojak (1998): Frankfurt am Main, New York: Campus, 181-205.

Bauer, F. (1965a). Fritz Bauer, Die Wurzeln faschistischen und nationalsozialistischen Handelns. Frankfurt am Main: Europäische Verlagsanstalt.

Bauer, F. (1965b). Im Namen des Volkes (1965). En Fritz Bauer, Die Humanität der Rechtsordnung. Ausgewählte Schriften. Ed. por Joachim Perels e Irmtrud Wojak (1998): Frankfurt am Main, New York: Campus, 77-90. 
Bauer, F. (1965c). Antinazistische Prozesse und politisches Bewußtsein: Dienen NS-Prozesse der politischen Aufklärung? En Antisemitismus: Zur Pathologie der bürgerlichen Gesellschaft. Ed. por Hermann Huss y Andreas Schröder (1965): Frankfurt am Main: Europäische Verlagsanstalt, 168-193.

Bauer, F. (1966). Auf der Suche nach dem Recht. Stuttgart: Franckh'sche Verlagshandlung.

Bauer, F. (1968). Ungehorsam und Widerstand in Geschichte und Gegenwart. Online: http://www.humanistische-

union.de/nc/wir_ueber_uns/geschichte/geschichtedetail/back/geschichte/article/ungehorsamund-widerstand-in-geschichte-und-gegenwart/ (25.07.2015), Artículo en Vorgänge Nr. 89/1968, 286-292.

Buchheim, H., Broszat, M., Jacobsen, H. y Krausnick, H. (1965). Anatomie des SS-Staates. Tomo I y II. Olten und Freiburg im Breisgau: Walter.

Fröhlich, C. (2006). Wider die Tabuisierung des Ungehorsams. Fritz Bauers Widerstandsbegriff und die Aufarbeitung von NS-Verfahren. Frankfurt am Main, New York: Campus.

Gruen, A. (2002). Der Fremde in uns. Quinta Edición Stuttgart: Klett-Cotta.

Gruen, A. (2015). Wider den Gehorsam. Sexta Edición Stuttgart: Klett-Cotta.

Constitución de la República Federal Alemana (Grundgesetz der Bundesrepublik Deutschland, GG).

Kempner, R. (1969). Ohne Titel: Trauerrede. Hessisches Ministerium der Justiz (Ed.), Fritz Bauer. In Memoriam. Wiesbaden: Hessisches Ministerium der Justiz, 23-26.

Langbein, H. (1995). Der Auschwitz-Prozeß: Eine Dokumentation. 2 Tomos. Wien 1965, Nueva edición Frankfurt am Main: Büchergilde Gutenberg.

Molitor, J. (1952), Die Schatten der Toten vom 20. Juli... . Die Zeit, 11: http://images.zeit.de/text/1952/11/Zt19520313_002_0007_p.

Staff, I. (1968). In Memoriam Fritz Bauer. Tribüne. Zeitschrift zum Verständnis des Judentums. 7 (27), 2857-2859. 
Staff, I. (1988). Fritz Bauer (1903-1968). Im Kampf um des Menschen Rechte“. Kritische Justiz (Ed.), Streitbare Juristen. Eine andere Tradition. Baden-Baden: Nomos, 440-450.

Wojak, I. (Ed.) (2004). Auschwitz-Prozeß. 4 Ks 2/63. Frankfurt am Main. Köln, Gent: Snoek. Wojak, I. (2009). Fritz Bauer (1903-1968). Eine Biographie. München: C. H. Beck.

Wojak, I. (2013). Eichmanns Memoiren. Mythos und Wirklichkeit. Con prólogo de Hans Mommsen, Berlin: Gemini. 